\title{
Using Debate to Promote Students' Reflective Understanding of Research Ethics
}

\author{
Monica Eviandaru Madyaningrum \\ Faculty of Psychology \\ Sanata Darma University \\ memadyaningrum@usd.ac.id
}

\begin{abstract}
This article reported a qualitative study that examined the use of debate to promote students' reflective understanding of research ethics. The study was conducted in a qualitative methodology class for undergraduate students in psychology. Data were collected from 36 students attending the class by using an open-ended questionnaire. There were four questions in the questionnaire which were intended to gange students' understanding of ethical issues in qualitative research. The questionnaire was distributed twice, before and after the students engaged in the debate. During the debate, the students had to argue about dilemmatic research situations that reflected ethical issues in research. Thematic analysis was used to qualitatively examine and compare the students' responses, before and after the debate. The findings suggested four themes that represented a shift in the students' understanding of research ethics. These themes indicated the emergence of more contextual and reflective views of research ethics among the students.
\end{abstract}

Keywords: debate, teaching ethics, reflective learning.

Received 23 December 2021/Accepted 27 February 2022 @A Author all rights reserved

\section{Introduction}

Developing students' ethical competence is a central part of psychology education, including at the undergraduate level (Bersoff, 2003). In the context of research training, building students' ethical orientation entails a process of developing knowledge and skills for conducting research in morally accountable manners (King, 20I0). Whilst the importance of teaching ethics, including ethics in research practices, have been emphasized, yet there remains limited literature that discuss strategies and methods for teaching ethics, especially in undergraduate levels (Burr \& King, 2012; Healey, Ribchester \& Ross, 20II; Löfström, 20I2). 
A similar situation has also been found in the Indonesian context, as reflected in a workshop organized by the Indonesian Psychological Association (Yogyakarta chapter) on September 2019. The aim of the workshop was to identify common concerns, needs and challenges in regard to teaching ethics in psychology programs. The workshop involved psychology lecturers from a number of universities in Yogyakarta, including the author. One of the challenges highlighted in the workshop was the lack of references that discussed strategies and methods for teaching ethics, including ethics in research and publications. This workshop underlined the need for developing and disseminating innovative ways of teaching ethics. Encouraged by this gap, this article described the author's attempt to explore an engaging way of teaching research ethics.

Other than encouraged by the gap in the literature, the author's interest in exploring innovative ways of teaching research ethics was also inspired by references that argue about the importance of promoting reflective learning in the teaching of ethics (e.g., Biggerstaff, 2005; Branch \& George, 2017; Hedberg, 2017 ; Jones, Rivas, \& Mancillas, 2009; Kyle, 2008). Reflective learning represents processes through which students are encouraged to actively situate the subject matters that they are learning about in their own personal and social contexts (Kyle, 2008). In the case of teaching research ethics, reflective learning describes students' ability to recognize and examine their own values and moral orientations and how these may influence the way they perceive and conceptualize ethical conducts in research (Hedberg, 2017 ; Jones et al., 2009; Kyle, 2008).

A number of references on the teaching of ethics (e.g., Cunliffe, 2004; Hedberg, 2017) suggest that reflective learning can be stimulated through questions that encourage students to relate their own prior knowledge, experiences and assumptions to the ethical issues being discussed in the subject. The examples for such questions may include: what it means for them to learn about the principles of research ethics; to what extent these principles are consistent with their own values and assumptions; or how they will manage psychological discomforts that may emerge as a consequence of applying ethical principles in their study (Cunliffe, 2004). Using this kind of questions to facilitate students' learning is considered crucial in the teaching of ethics as it may enable students to approach ethical issues not 
merely as intellectual or legal problems. Rather, reflective learning encourages students to focus on the moral dimensions of ethical issues, which often demand more complex considerations, beyond what are formally regulated in the codes of ethics (Healey et al., 20I I; Hedberg, 20I7).

Therefore, as suggested in a number of studies (e.g., Burr \& King, 2012; Grose-Fifer, 2017; Healey et al., $20 \mathrm{II}$, Kyle, 2008), didactic models of teaching (e.g., teacher-centered lecturing) that primarily targeting at students' abstract comprehensions of ethical principles are considered less relevant. Such methods create less possibilities for students to reflectively engage with the issues being discussed. Instead, the learning of ethics requires methods that encourage students' active participation and allow them to learn from situations or experiences that have real-world relevant (Burr \& King, 20I2; Grose-Fifer, 20I7; Kyle, 2008; Healey et al., 20I I; Hedberg, 20I7; Naimi, 2007; Sim, Sum \& Navedo, 20I5).

A number of scholars argue that introducing students to realistic cases that represent ethical issues and conflicts can promote students' deeper understandings of research ethics (e.g., Healey et al., 20II; Löfström, 2012, Ozolins, 2005). Having exposure to various examples of ethical issues and conflicts in research may also enable students to recognise the nature of ethical problems which are often ambiguous and not as straightforward as how ethical principles are generally outlined in textbooks and guidelines. Gaining this kind of understanding is crucial for developing students' ability to make cognisant ethical discernments in their research (Healey, et al., 20 I I; Hedberg, 2017, Ozolins, 2005).

Informed by these literatures, the current article describes the author's attempt to explore a non-didactic way of teaching research ethics. The author was particularly interested in exploring a teaching method that may promote students' reflective learning and better understanding on the complexities of ethical issues in qualitative research.

The potentials of using debate to teach research ethics

The previous section highlights the importance of reflective learning in the teaching of ethics. Whilst a number of references have supported the value of reflective approaches in the teaching of ethics, further 
studies are needed to explore teaching methods that may effectively put these approaches into practice (Healey et al., 20lI). Such a need is even greater in the Indonesian context, as studies that explore methods for teaching ethics are still rare. Informed by this gap, this current study examines the potential of using debate as a method for teaching and learning about research ethics in an engaging way. Debate as a teaching method appears to have some characteristics which are suitable to facilitate students' reflective learning.

The potentials of debate as a teaching method have been reported in numerous studies (e.g., Bradshaw \& Lowenstein, 2007; Darby, 2007; Griswold, 2000; Hanna, et al., 2014; Scott, 2009; Zare \& Othman, 2013). When debate is used as a teaching method, students are usually exposed to dilemmatic cases or competing issues upon which they have to make their arguments, whether as an individual or in a group. It is through such a process that students are encouraged to engage in higher order of thinking as they have to analyse, synthesize and evaluate (Bradshaw \& Lowenstein, 2007). In general, debate as a teaching method has been positively valued for its ability to foster students' active participation (Bradshaw \& Lowenstein, 2007; Griswold, 2000; Scott, 2009; Zare \& Othman, 2013), to promote analytical and critical thinking (Bradshaw \& Lowenstein, 2007; Brown, 20I5; Darby, 2007; Hall, 20I I; Scott, 2009), as well as to advance students' communication skills (Darby, 2007; Hall, 20II). Debate is considered effective for promoting these outcomes as it requires students to conduct series of complex learning activities, such as collecting relevant data, systematically comparing and analysing those data, developing convincing arguments, as well as conveying ideas and opinions in persuasive ways (Bradshaw \& Lowenstein, 2007; Brown, 2015).

In addition, as debate requires students to exchange thoughts and views, therefore, this method may be useful for facilitating students' ability to observe and learn from diverse ways of thinking, including those which are contradictory to their own perspectives and beliefs. Hence, through a debate, students may find their standpoints being questioned, doubted or even challenged (Brown, 20I5). It is because of such characteristics that debate may function as a suitable method for promoting students' reflective learning. As highlighted by Hsiung (2008), students need to engage in critical dialogues, with other people as well 
as with their own self, to be able to think reflectively. Having dialogues with others may serve as a mirror through which students can better recognise their own assumptions, values, thoughts and beliefs, as well as the strengths and limits of their ways of thinking. It is such an ability that constitutes a reflective learning. Drawing on these references and arguments, the author was interested in exploring how debate may promote students' reflective learning about research ethics.

Debates have been reported as an effective way for teaching issues or topics which are conflicting or dilemmatic, as it creates possibilities for students to explore and raise various points of view to the issues or topics being discussed (Bradshaw \& Lowenstein, 2007; Brown, 2015). Such a characteristic is in line with the nature of ethical issues in research which are often ambiguous and may therefore cannot be easily responded in a strictly right or wrong perspective, rather it requires more nuanced considerations (Askins, 2008). Informed by these references and arguments, the author sought to understand how debates may expand students' understanding on ethical issues in qualitative research.

\section{Method}

\section{Study design}

This study was informed by methods commonly employed in educational research, particularly those which are generally termed as classroom-based action research (Johnson \& Christensen, 20I2; Ladico, Paulding \& Voegtle, 2010) or in the Indonesian context is popularly known as riset tindakan kelas (Suparno, 2008). This type of research is usually conducted by teachers or lecturers in their attempt to investigate the effectiveness of educational interventions such as the use of a particular teaching method to promote or achieve targeted learning outcomes.

The use of both qualitative and quantitative designs is common in this kind of study; however, the methodological designs are generally simpler than theoretically driven empirical research (Johnson \& Christensen, 2012; Ladico, Paulding \& Voegtle, 2010). In general, classroom-based research are focused on finding solutions for specific questions or problems dealt by the teachers or lecturers in their teaching practices. Therefore, the findings are usually positioned more as a preliminary insight to better 


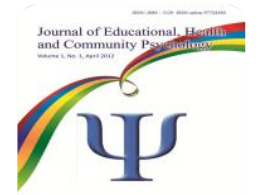

Journal of Educational, Health and Community
Psychology (Vol 11, No 1, 2022 E-ISSN 2460-8467)

Madyaningrum

understand the particular method, class or group being studied or evaluated, rather than as generalizable conclusions (Suparno, 2008). Drawing on these premises, in this current study, the author used a qualitative approach to examine the benefits of using debate as a method for teaching research ethics.

\section{Research participants}

The participants of the study were 36 out of 43 students who attended the author's qualitative methodology class in the odd semester of 2019/2020 academic year. They were fifth semester undergraduate students. The author used two strategies to ensure voluntary participation in the study. Firstly, the students were asked to respond to the questionnaire anonymously. Secondly, the author emphasized the students' right for not participating in the study. The questionnaire was distributed to all of the students attended the class, and if they did not feel like to participate in the data collection, they could hand back a blank questionnaire without feeling worried of being personally identified. With these strategies, the author wanted to minimize the possibilities of students feeling obliged to respond to the questionnaire due to the author's position as the lecturer of the class. 43 questionnaire forms were distributed and returned; seven of those were blank questionnaire.

\section{Data Collection}

Data were collected in a session where discussing ethical issues in qualitative research became the main learning topic. Before the session was started, the author explained to the students that they were invited to respond to a questionnaire, which aimed to explore their reflections on the learning activity that they would be doing. It was also mentioned that the questionnaire would be distributed twice, in the beginning and in the end of the class. In addition, the students were also informed that their responses would not be used to assess students' achievement, rather the result would be used to evaluate the effectiveness of the teaching method applied in the session. The questionnaire consisted of four open ended questions as presented in table I. 


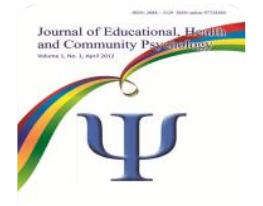

Journal of Educational, Health and Community
Psychology (Vol 11, No 1, 2022 E-ISSN 2460-8467)

Madyaningrum

Table I

Survey Questions

\begin{tabular}{|c|c|c|}
\hline Number & Questions & The aim of the question \\
\hline I & $\begin{array}{l}\text { In my understanding, research ethics can be defined } \\
\text { as ... }\end{array}$ & $\begin{array}{l}\text { To explore how the students define } \\
\text { research ethics }\end{array}$ \\
\hline 2 & The main purposes of research ethics are... & $\begin{array}{l}\text { To explore how the students describe } \\
\text { the aims of research ethics }\end{array}$ \\
\hline 3 & $\begin{array}{l}\text { To be able to apply research ethics appropriately, } \\
\text { researchers need to ... }\end{array}$ & $\begin{array}{l}\text { To explore how the students define } \\
\text { ethical competence }\end{array}$ \\
\hline 4 & $\begin{array}{l}\text { Challenges and difficulties that researchers may } \\
\text { encounter when applying research ethics principles } \\
\text { in their study are... }\end{array}$ & $\begin{array}{l}\text { To explore how the students describe } \\
\text { ethical challenges in research }\end{array}$ \\
\hline
\end{tabular}

Open ended questions were used as these allowed this study to explore in vivo themes which represented the students' thoughts and concerns in relation to the topic being studied. The use of open-ended survey questions in educational research is common, especially when the study is intended to explore students' views and comments on particular issues, as this method allows students to respond to the questions in their own words (Johnson \& Christensen, 20I2).

In addition, informed by Bloom's taxonomy (1956), the questions in the questionnaire were designed in a way that allowed the students to start their reflections by using simple cognitive processing (e.g., remembering and explaining) and then moved toward more complex processes, such as evaluating and analyzing. The questionnaire was distributed twice, before and after the debate process.

\section{Procedure}

Prior attending the class, the students were asked to read a reference (i.e., chapter 5 of Willig, 2013), which contained information about some basic principles of research ethics (e.g., beneficence, nonmalfeasance, informed consent, confidentiality, and right to withdraw). The session was started by asking 
the students to respond to the questionnaire. After that, the author presented a brief lecture that summarized the reading. This process was also used to gauge students' understanding of the reading and to address any question or confusion that the students might have. After the students indicated that they had understood the meaning of each ethical principle being discussed in the reading, the author then invited them to do the next activity, which was a classroom debate.

The debate topics were fictional cases, which were designed to expand the students' understanding of research ethics principles. All of the cases were deliberately designed to represent complex ethical issues that encouraged the students to think beyond what were formally defined in the recommended reference. Each case described a dilemmatic situation with two response options and every student had to choose one of those. Each option entailed challenging consequences; therefore, it required the students to think analytically and carefully before they made their choice. This process was also intended to encourage the students' reflective and critical thinking by realizing the rationales and assumptions that underpinned the responses they opted for.

The following excerpt describes one of the fictional cases presented in the class:

Along the process of doing a qualitative research project, you have gradually built good relationships with families who are involved as the research participants. The generous support that you constantly get from these families have made you feel greatly indebted to them. Through your interactions, you have also witnessed the daily struggle that these families have to go through due to poverty. During the data collection process, one of these families asks you to borrow some money to cover the school fee of their child. The amount asked is quite small according to your financial capacity. How would you respond to their request? Lending them the money or refuse it? Which one will be considered as the more ethically appropriate response? Which research ethics principles is reflected in this case?

The quotation above was one out of five cases presented to the students. Each case represented a particular research ethical principle. For example, the case in the quotation above was used to stimulate 
a debate around the principle of voluntary participation. Each case required every student to choose a response, which he or she thought, would be the more appropriate action or attitude to be made in the dilemmatic situation being discussed.

After making their choice, every student was asked to sit together with those who chose a similar response. Through this process, the class was divided into two groups, with each had an opposing response to the dilemmatic situation presented in the case. Firstly, they were asked to share their thoughts in their group, and after that the two groups were invited to present their arguments and to debate based on what they perceived as the problematic considerations that the other group had. Each group was also asked to argue of why they thought that their response was more appropriate. In this debate process, every student in each group could voice their opinion and argument.

During the debate, the author took a role as the moderator and observer, including encouraging those who tended to be passive, intervening when there were dominating voices, probing and prompting key arguments to sharpen the discussion. In the end of the class, a debriefing session was conducted to address students' concerns or questions in relation to the debate process. The debriefing session was also used to link key notions emerge in the debate with the expected learning outcomes. Before the class was ended, the students were invited to respond to the same questionnaire distributed in the beginning of the class.

\section{Data analysis}

The data were analyzed by using thematic analysis as proposed by Braun and Clarke (2006). Thematic analysis was utilized as it provides systemic guidelines as well as flexibility to analyze rich and complex data generated by qualitative data collection tools, including those produced by questionnaires with openended questions (Braun \& Clarke, 2006).

Informed by Braun and Clarke's (2006) thematic analysis, the data analysis was conducted in five stages. It was started by gaining familiarity with the data. At this stage, the author conducted line-by-line close 
reading and re-reading all of the responses, both those which were generated before and after the debate. This process was then followed by developing initial codes or labels for each response. To ensure a systematic coding process, codes were created sequentially, from the pre-debate to the post-debate data. At this stage, the codes were in the forms of descriptive labels that could capture the key themes represented in the responses. For example, in the question that asked the students about their understanding of research ethic, a student responded, "research ethic is a guideline for conducting a study". The code created for such a response was "research ethic is a guideline"

The third stage of data analysis was searching for themes or main ideas that represent the students' responses for each question. At this stage, the author repeatedly compared all the descriptive codes to identify patterns or recurring ideas in the data. Descriptive codes which shared similar idea were grouped together under one theme. For example, these three descriptive codes or labels: I) research ethics is a guideline, 2) research ethics is a set of rules, and 3) research ethics is the standard of right and wrong, were grouped together under the theme of "research ethics as a regulation"

All of the themes generated in the third stage of data analysis were then reviewed to ensure their accuracy. This process became the fourth stage of the data analysis. At this stage, all of the key themes and the underpinning descriptive labels were repeatedly compared, sorted and resorted to ensure their accuracy.

In the last phase of the data analysis process, the author compared key themes that emerged in the predebate data to those found in the post-debate data. This comparison enabled the author to identify key differences or shifts that emerged in the students' responses. These key differences or shifts were then conceptualized as the final findings of the study. For example, by comparing key themes found in the students' responses to the first question (i.e., In my understanding, research ethics can be defined as ...), it could be identified that there was a difference in the way the students defined research ethics. Before the debate, the students tended to define research ethics as a regulation. Whereas, after the debate, the students appeared to associate research ethics with the notion of accountability. Based on this difference, 


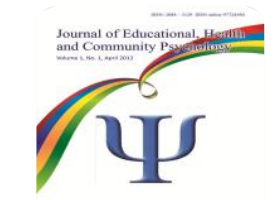

\section{Journal of Educational, Health and Community \\ Psychology (Vol 11, No 1, 2022 E-ISSN 2460-8467)}

the author then conceptualized the theme of 'from regulations to accountabilities' as the key finding for question one.

Peer-review was utilized to help refine the quality of the data analysis. The author involved a colleague who has a doctoral degree in psychology and extensive experiences in qualitative research to review the data analysis process. The feedback provided by this colleague were used to refine the formulation of the final themes.

Table 2

Findings of the Study

Topics

Key themes which reflect the shifts in the students' perceptions before and after the debate

I. How the students defined research ethic From regulations to accountabilities

2. How the students described the aims of research ethics

3. How the students defined ethical competence

From regulating to protecting

From mastering ethics as a set of knowledge and moral standard to exercising ethics as embodied practices

4. How the students described ethical challenges in From viewing a dilemmatic situation as a threat for research researchers to perceiving it as a risk for research participants

\section{Results}

The aim of this study was to examine how debate may promote students' reflective understanding of ethics in qualitative research. The analyses led to the identification of four findings which suggested the 
shifts in the way the students viewed research ethics and its complexities, before and after they were involved in the debate process. The four findings are outlined in table 2.

\section{Understanding of research ethics: from regulations to accountabilities}

This first theme represented the changes in the way the students defined research ethics, before and after they engaged in the debate process. Before participating in the debate, majority of the students tended to define research ethics as: I) regulations for conducting research, 2) rules that must be followed by researchers, or 3) as code of conducts for researchers. For example, such understandings are reflected in the following response from some of the students when they were asked about the definition of research ethics, "[research ethics is] a regulation that must be applied in research so that the study can go well" Prior to the debate, only small number of the students who associated research ethics with the need for protecting the rights and welfare of research participants.

However, after the debate, the students tended to respond to the first question (i.e., In my understanding, research ethics can be defined as ... ) in slightly different manners. The understanding of research ethics as regulations or code of conduct were still found in their responses, yet, they appeared to have more nuanced explanations about the role of research ethics. Before the debate, they tended to define research ethics merely as a set of regulation that must be followed by every researcher. After the debate, there were more responses that looked at research ethics as a set of regulation which first and foremost is needed for guaranteeing the welfare of research participants and researcher. They also mentioned about research ethics as a guidance for minimizing potential risks and harms, as well as for ensuring voluntary participation in a study. For example, after the debate a student wrote "research ethic is about prioritizing research participants' welfare and being mindful of how a study may impact broader social contexts where the study was conducted"

Such changes suggested that there was a shift in the ways the students understood research ethics, before and after the debate. Before the debate, they appeared to understand research ethics as a kind of 'do's and don'ts list' for conducting research. After the debate, however, they seemed to gain an 


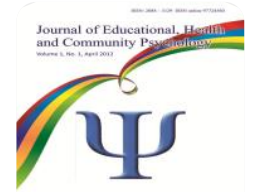

Journal of Educational, Health and Community

Psychology (Vol 11, No 1, 2022 E-ISSN 2460-8467)

Madyaningrum

understanding that research ethics was not merely a set of rules that researchers need to obey. Rather, research ethics were understood as essential guidelines needed for ensuring the accountability of a study.

Perceptions on the aims of research ethics: from regulating to protecting

Similar with the previous finding, the second finding also suggested the emergence of more nuanced understandings of research ethics among the students, after they engaged in the debate process. Before the debate, there were two patterns of responses that described the ways the students understood the aims of research ethics. They explained that the aims of research ethics were for regulating researchers' conducts and for ensuring research participants' welfare. After the debate, however, there were no longer responses which suggested that the aims of research ethics were for regulating researchers' conducts. The post-debate responses were mainly associated the aims of research ethics with the roles of researchers to ensure research participants' welfare and to minimize research risks.

In line with the previous finding, this second finding also suggested that participating in the debate enabled the students to gain broader understandings of research ethics. They no longer viewed research ethics mainly as a kind of behaviour control or constraint for researchers. Rather they appeared to develop an understanding that research ethics is an integral part of maintaining research accountability which are necessary for protecting both the welfare of research participants and researchers. Such an understanding was exemplified in the following response, "After joining the debate, now I know that the main aim of research ethics is for ensuring the wellbeing of research participants"

Perceptions on ethical competence: from mastering ethics as a set of knowledge and moral standard to exercising ethics as embodied practices

This third finding suggested the shift in the ways the students understood the meanings of ethical competence. This finding was drawn from the students' responses to the third question in the questionnaire (i.e., To be able to apply research ethics appropriately, researchers need to ...). Before the debate, the students tended to associate ethical competence with the idea of having comprehensive knowledge about ethical principles, especially those written in the Indonesian Psychological Association 
Code of Ethics. The students also associated ethical competence with the idea of having good morals. This kind of view was illustrated in the following excerpts: "[to gain ethical competence, a researcher needs to]: I) having awareness about the importance of research ethics, 2) reading the Indonesian Psychological Association Code of Ethics, and 3) having good morals".

Similar findings were found in the post-debate responses. After the debate, the students also associated ethical competence with the idea of having vast knowledge about ethical principles. However, there were also responses that indicated a shift in the way the students perceived ethical competence. After the debate, some students mentioned that researchers need to be reflective in their research in order to gain ethical competence. In addition, they explained that using reflective approaches to research might help researchers to make informed decisions about their study. Such a shift was illustrated in the following response: "[to gain ethical competence researchers need to] reflect on who might be benefited by their study and who might be harmed by it" There was also a student who wrote, "“'[to gain ethical competence researchers need to] be able to differentiate between the better and the worse and not merely think about right or wrong". This kind of responses indicated an understanding of ethical competence that was broader than just mastering knowledge on code of ethics. Some students appeared to comprehend that practising reflective reasoning was also an important part of gaining ethical competence. Thus, they recognised that achieving ethical competence required researchers' willingness to exercise ethics as embodied practices.

Perceptions on ethical challenges: from viewing a dilemmatic situation as a threat for researchers to perceiving it as a risk for research participants

Both before and after the debate, the students perceived dealing with dilemmatic situations as the main ethical challenge in research. As illustrated in the cases used to facilitate the debate, an example of such a dilemma was dealing with a research participant who asked for a personal favour to the researcher which might jeopardize the principle of voluntary participation in a study. The dilemmatic nature of the cases used in the debate might have led such a perception among the students. However, there was a shift in the way the students viewed dilemmatic situations in research. 
Before the debate, the students tended to view dilemmatic situations in research as a kind of threat to the study or a hurdle for researchers. Such views were reflected in comments like: "dealing with ethical dilemmas may limit types of information that can be collected in a study" or "dealing with dilemmatic situations may cause researchers to postpone their data collection process". After the debate, however, there were more responses which implied an understanding that dealing with dilemmatic situations in research is common and that researchers need to prioritize the wellbeing of research participants when dealing such situations. This kind of understanding was illustrated in this excerpt, "there are grey areas in research, therefore, it is not always easy to hold fast on one thing in a study without considering the wellbeing of research participants". It was such a shift that suggested the emergence of more complex understanding of ethical issues in qualitative research.

\section{Discussion}

This study sought to explore how debate may promote students' reflective learning about research ethics. The findings suggested that through their participation in a debate, the students in this study were enabled to develop more nuanced understandings of research ethics. Before participating in the debate, the students tended to view research ethics in procedural perspectives. In this sense, research ethics were mainly understood as rules that researchers have to comply with. As a result, research ethics seemed to be viewed as restrictions or even hurdle for researchers rather as a key measure of research credibility. In addition, such understandings also implied that the students mainly focused on ethics as textual knowledge.

After participating in the debate where the students were exposed to a number of ethical dilemmas, there seemed to be a shift in the way the students viewed research ethics. Through this learning activity, the students were enabled to view research ethics not only as regulations, but also as contextual practices intended to ensure beneficence in research. Such a shift was reflected in the post-debate comments where the students seemed to emphasize the importance of putting the welfare of research participants first when dealing with dilemmatic situations in a study. By gaining an understanding of 
research ethics as contextual practices, the students were then able to recognise complex considerations that researchers may have to deal with when implementing code of ethics in real world settings. Through this learning activity, the students might also realize the importance of going beyond procedural ethics in order to discern moral issues in research contexts. It was these findings that suggested the emergence of reflective understanding of research ethics among the students.

The cases used in the debate did condition the students to think beyond what are formally regulated in the code of ethics. The dilemmatic situations described in the cases encouraged the students to look at complex factors that may influence how researchers address ethical issues in a study. However, exposing the students to those cases alone might not trigger the emergence of reflective understanding of ethical issues, if the cases were not discussed in a form of classroom debate. The use of debate prompted the students to think conscientiously about the ethical issues being discussed, as they had to exchange, challenge and defend opinions. This point was reflected in the students' comments when they were asked to give feedback on the use of debate in the class. Some of the students wrote positive evaluations about the debate as this method encouraged them to think critically about the topics. A couple of examples of such evaluations were: "[with the use of debate], we did not passively receive the study materials, but we had to think independently about the topics" and "[the use of debate] encouraged me to think critically and make decisions". It was these findings that suggested how the debate might have enabled the students to think reflectively about ethical issues in qualitative research.

With such findings, this study supports previous literature (e.g., Brown, 20I5; Hsiung, 2008) which highlighted the strengths of debate as a teaching strategy. Consistent with these literatures, this study found that the use of debate encouraged the students to engage in critical dialogues from which they were enabled to rigorously examine and contrast, both their own and other people's thoughts and assumptions. In addition, as the debate exposed the students to competing perspectives on ethical issues, this allowed them to recognise the nature of ethical problems in research which are often ambiguous and cannot be merely approached as intellectual or legal problems (Askins, 2008; Healey et al., 20II; Hedberg, 2017). For example, when the students had to debate about whether or not researchers shall 
lend money to their research participants, some students argued that lending money would jeopardize the principle of voluntary participation, on the other hand, some students insisted that lending money was necessary on the basis of compassion. Through such an experience, the students could learn that dealing with conflicting values and competing obligations may become a part of managing ethical issues in research. As suggested by Askins (2008), gaining such experiences is crucial for developing students' reflective and contextual understandings of research ethics.

\section{Implications and limitations}

The findings of this study suggested that debate could provide an engaging way for learning about ethics in qualitative research. In addition, this study found that debate had some features which were useful for developing reflective and contextual understandings of research ethics. These findings support the use of debate to teach research ethics and to promote students' reflective learning on this topic.

However, this study was conducted in the author's classroom and this could be a limiting factor as this might pose a risk for researcher bias. Moreover, there was no other researcher or observer involved during the session which might strengthen the risk for researcher bias as there was no external control or comparison to the author's views of the session. The small number of participants involved in this study also became a limitation. Further studies are needed to examine the extent to which the findings reported in this study are supported in other contexts.

Furthermore, by focusing on identifying the strengths of debates as a method for teaching research ethics, the author might have overlooked the negative evaluations that the students might have on this method. As indicated in the students' feedback, there were a couple of students who mentioned that the use of debates might exclude those who tended to be passive in a group activity or anxious about expressing their voices. This feedback points to the need for considering different tools for evaluating students' experiences with the use of debates as a teaching method. For example, using focus group discussion may create more possibilities for having two-ways conversations with the students being studied, rather than using an open-ended questionnaire. 


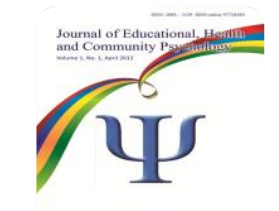

Journal of Educational, Health and Community
PSychology (Vol 11, No 1, 2022 E-ISSN 2460-8467)

Madyaningrum

\section{Conclusion}

This study qualitatively examined the use of debate to promote students' reflective learning about research ethics. The findings suggested that debate could function as an engaging way for learning about research ethics in reflective manners as this method encouraged critical conversations and generate various points of views on the topics being studied. With such findings this study supported previous literatures which had emphasized the strengths of debates as a teaching method. In addition, this study added to the literature by specifically investigating the benefits of using debate to promote reflective learning about research ethics.

\section{References}

Askins, K. (2008). In and beyond the classroom: research ethics and participatory pedagogies. Area, 40(4), 500-509. https://www.jstor.org/stable/40346/55

Bersoff, D. N. (2003). Introduction. In D. N. Bersoff (Ed.), Ethical conflicts in psychology ( ${ }^{\text {rd }}$ edition). Washington, DC: American Psychological Association.

Biggerstaff, M. A. (2005) Social work ethics online: Reflective learning. Journal of Technology in Human Services, 23(3-4), 245-257. https://doi.org//0.1300/J017v23n03_06

Bloom, B. S., Engelhart, M. D., Hill, W. H., Fürst, E. J., \& Krathwohl, D. R. (1956). Taxonomy of educational objectives. Handbook I: cognitive domain. New York, NY: David McKay Company.

Brach, W. T. \& George, M. (2017). Reflection-based learning for professional ethical formation. AMA Journal of Ethics, 19(4), 349-356. https://doi.org/I0.100I/journalofethics.2017.19.4.medul-I704

Bradshaw M. J., \& Lowenstein, A. J. (2007). Debate as a teaching strategy. In Bradshaw, M.J., \& Lowenstein, A. J. (Eds.), Innovative Teaching Strategies in Nursing and Health Related Professions (4th ed.) (pp. 15I159). Boston, MA: Jones and Bartlett.

Braun, V., \& Clarke, V. (2006). Using thematic analysis in psychology. Qualitative Research in Psychology, 3(2), 77-10I. https://dx.doi.org/I0.1 I9I/ 1478088706qp063oa

Brown, Z. (2015). The use of in-class debates as a teaching strategy in increasing students' critical thinking and collaborative learning skills in higher education. Educational Futures, 7(I), 39-55.

Burr, V. \& King, N. (20I2). 'You're in cruel England now: Teaching research ethics through reality television. Psychology Learning and Teaching, II(I), 26-29. https://dx.doi.org/I0.2304/plat.20I2.I I.I.22 
Cunliffe, A. L. (2004). On becoming a critically reflexive practitioner. Journal of Management Education, 28, 407-426. https://doi.org//0.1I77//0525629/66689/9

Darby, M. (2007). Debate: A teaching-learning strategy for developing competence in communication and critical thinking. Journal of Dental Hygiene, 8I (4), I-I0. PMID: 18173892

Griswold, L. (2000) Debate as a teaching strategy. American Journal of Occupational Therapy, 54(4), 42728. https://doi.org//0.50I4/ajot.54.4.427

Grose-Fifer, J. (2017). Using role play to enhance critical thinking about ethics in psychology. In R. Obeid, A. M. Schwartz, C. Shane-Simpson, \& P. J. Brooks (Eds.) How we teach now: The GSTA guide to student-centered teaching. Retrieved from http://teachpsych.org/resources/Documents/ebooks/gstaebook.pdf

Hanna, L. A., Barry, J., Donnelly, R., Hughes, F., Jones, D., Laverty, G., ... Ryan, C. (2014). Using debate to teach pharmacy students about ethical issues. American Journal of Pharmaceutical Education, 78(3) 57. doi.org// 0.5688/ajpe78357

Hall, D. (20I I). Debate: Innovative teaching to enhance critical thinking and communication skills in healthcare professionals. Internet Journal of Allied Health Sciences and Practice, 9(3), I-8.

Healey, R. L., Ribchester, C., \& Ross, K. (20I I). 'The ethical student': Enhancing the teaching of ethics in the undergraduate curriculum. Learning and Teaching Institute, University of Chester. Retrieved from https://www.chester.ac.uk/sites/files/chester/Ethical\%20Student.pdf

Hedberg, P. R. (2017). Guiding moral behavior through a reflective learning practice. Journal of Management Education, I - 25. https://doi.org/I0.1 I77/10525629/7695/99

Hsiung, P.-C. (2008). Teaching reflexivity in qualitative interviewing. Teaching Sociology, 36, 21 I-226. https://doi.org// 0.1 I77/0092055X0803600302

Johnson, B., \& Christensen, L. (20I2). Educational research: Quantitative, Qualitative and mixed approaches ( $4^{\text {th }}$ edition). Los Angeles, CA: SAGE

Jones, I. S., Rivas, O., \& Mancillas, M. (2009). A model for teaching ethical meta-principles: A descriptive experience. Teaching and Learning Faculty Publications and Presentations, 12. Retrieved from https://scholarworks.utrgv.edu/tl_fac/I2

King, N. (2010). Research ethics in qualitative psychology. In M. A. Forrester (Ed.). Doing qualitative research in psychology (Pp. 98 - II8). London; SAGE Publications Ltd.

Kyle, G. (2008). Using anonymized reflection to teach ethics: A pilot study. Nursing Ethics, I5(I), 6-16. https://doi.org// 0.1 I77/096973300708393 I

Lodico, M. G., Spaulding, D. T., \& Voegtle, K. H. (2010). Methods in educational research: From theory to practice $\left(2^{\text {nd }}\right.$ edition). San Fransisco, CA: Jossey-Bass 
Löfström, E. (20I2). Students' ethical awareness and conceptions of ethics. Ethics \& Behavior, 22(5), 34936I. https://doi.org//0.1080//0508422.2012.679/36

Naimi, L. (2007). Strategies for teaching research ethics in business, management and organisational studies. The Electronic Journal of Business Research Methods, 5(I), 29-36.

Ozolins, J. T. (2005). Teaching ethics in higher education: In A. Brewer and C. Asmar (Ed.). Higher education in a changing world: Research and development in higher Education. (pp. 358 - 364). Hammondville, NSW: Higher Education Research and Development Society of Australasia.

Scott, S. (2009). Perceptions of students' learning critical thinking through debate in a technology classroom: a case study. The Journal of Technology Studies, 34, 39-44. https://doi.org//0.21061/jots.v34il.a.5.

Sim, K., Sum, M. Y., \& Navedo, D. (2015). Use of narratives to enhance learning of research ethics in residents and researchers. BMC Medical Education, 15(4I). https://doi.ord/I0.1186/s/2909-0I50329-y

Suparno, P. (2008). Riset tindakan untuk pendidik. Jakarta: PT. Gramedia

Willig, C. (2013). Introducing qualitative research in psychology. Buckingham, UK: McGraw-hill education (UK).

Zare, P., \& Othman, M. (2013). Classroom debate as a systematic teaching/learning approach. World Applied Sciences Journal, 28(II), I506-15I3. 